\title{
Textos de divulgação científica (TDC) nas aulas de Biologia na Educação de Jovens e Adultos (EJA) para abordar a temática alimentação
}

\section{Popular science texts in biology classes in the Education of Youth and Adults Education to address the theme of food}

\author{
${ }^{1}$ Lidiane Loiola de Oliveira \\ ${ }^{2}$ Mariana de Senzi Zancul | marianaib@unb.br
}

\begin{abstract}
RESUMO
A escola é, por excelência, um local propício à divulgação de ideias novas e ao desenvolvimento de ações que envolvam diversos temas. Este trabalho teve como objetivo usar textos de divulgação científica como estratégia de ensino em Educação em Saúde na escola, visando despertar o interesse e a sensibilização dos alunos. A ação educativa foi realizada no $2^{\circ}$ semestre de 2012 com alunos matriculados na Educação de Jovens e Adultos numa escola pública do Distrito Federal (DF). Os resultados indicaram que os textos de divulgação científica despertam o interesse e uma participação efetiva dos alunos nas discussões, uma vez que relacionavam os assuntos de saúde com o cotidiano dos estudantes, favorecendo a partilha de suas experiências e a troca de saberes. Nota-se também que a mediação do professor nas discussões e na escolha dos textos de divulgação científica são fundamentais para o sucesso deste tipo de ação.
\end{abstract}

Palavras chave: Ensino de Ciências, Educação em Saúde, Textos de Divulgação Científica, Educação de Jovens e Adultos.

\section{ABSTRACT}

The school is, par excellence, a place favorable to dissemination of new ideas and development of actions involving various themes. This study had as primary objective the use of popular science texts as a strategy for health education in school, in order to draw students attention and their awareness. The educational activity, composed of various pedagogical activities, was held in the 2nd semester of 2012 with students enrolled in Youth and Adult Education in a public school in the Federal District. The results indicated that the introduction of popular science texts arouse greater interest and more effective participation of students in discussions, once texts related health themes to the daily lives of these students, favoring the share of experiences and knowledge. However, note that the teacher participation in texts selection and his mediation during debates are important steps to the success of this kind of action.

Keywords: Science Education, Health Education, Popular Science Texts, Young People and Adult Educations

1 Aluna do Programa de Pós-graduação em Ensino de Ciências da UnB.

2 Docente do Programa de Pós-Graduação em Ensino de Ciências da UnB/ Instituto de Ciências Biológicas - UnB Brasília. 


\section{INTRODUÇÃO}

A vida moderna é marcada pela presença constante da ciência e tecnologia, pré-requisitos essenciais para a resolução de questões econômicas e sociais. E com este enfoque, para uma formação cidadã plena é necessária a aquisição de conhecimentos mínimos a respeito da ciência e seus mecanismos de funcionamento, que possibilitem entender o seu meio, expandir suas oportunidades no mercado de trabalho e favorecer uma atuação crítica consciente (MOREIRA, 2004). Para isso é necessário aprender a ler e entender muito mais do que conceitos superficiais a respeito de Ciência e Tecnologia, com suas implicações e consequências, visando uma participação mais efetiva nas decisões de ordem política e social (PINHEIRO, et al., 2007; SANTOS, 2008).

Nesse contexto, a divulgação científica tem papel importante, na formação de cada indivíduo, no aumento de sua capacitação científico-tecnológica e no fomento de uma cultura científica, e até mesmo na complementação do ensino de ciências, por vezes deficiente em nosso país (MOREIRA, 2004).

Nos últimos anos, segundo Aires et al. (2003), a divulgação científica tem crescido no Brasil, com diversas iniciativas, como jornais, museus, programas de televisão, feiras e, principalmente, revistas. Além disso, é interessante ressaltar que a divulgação científica vem ganhando novo sentido, se voltando também para os aspectos éticos e para a reflexão de suas consequências para a sociedade.

A divulgação científica está presente no dia a dia das sociedades modernas, nos mais diversos espaços e meios de comunicação. A ciência, portanto, não está limitada a um único meio para sua difusão, estando presente em revistas, jornais, televisão, cinema, museus, exposições, livros e outros (ZAMBONI, 2001).

Sendo assim, muitos pesquisadores têm assinalado a divulgação científica com propósito social preferencial, ou seja, como uma condição básica para o desenvolvimento dos indivíduos e suas sociedades, uma vez que a Ciência pode ser apresentada como uma alternativa para a compreensão e interação com o mundo, favorecendo os mecanismos de inclusão e democratização do conhecimento (BUENO, 2002).

De acordo com Kreinz, (2004), a divulgação científica tem duas importantes funções complementares, a primeira é a função de ensinar, provendo ou acrescentando à função da escola, e segundo, a função de incentivar o ensino.

No entanto, a divulgação científica não se apresenta com objetivos didático-pedagógicos ou com a finalidade de formar especialistas ou aperfeiçoar peritos. Entre seus objetivos estão a chance de expor resultados das pesquisas e seus mecanismos de construção do conhecimento a um público leigo. Para isso, são valorizadas as situações que há relação direta com o dia a dia dos leitores, favorecendo a contextualização dos conhecimentos na mente do leitor ou provocando extrusões com o saber cotidiano (ROCHA, 2010).

Como ressalta Silva (2003), espera-se que os conhecimentos oferecidos pelos diversos meios de comunicação sejam aproveitados pela escola, oportunizando atividades de reflexão a respeito do que se propala, promovendo a apropriação de outras formas de expressão e linguagem e propiciando uma contribuição para a qualidade da ação escolar.

Baseando-se nas novas concepções do ensino, que têm como pressupostos formar cidadãos críticos e atuantes na sociedade, os textos de divulgação científica (TDC) podem se firmar como um respeitável recurso didático, complementando os materiais tradicionais (ROCHA, 2010).

Deste modo, a utilização de TDC passa a ter denotação diferente, indo ao encontro das recomendações curriculares, contidas nos Parâmetros Curriculares Nacionais (PCN) de Ciências Naturais que destacam a importância da familiarização dos estudantes com diversos tipos de textos científicos, o que permite a expansão de suas possibilidades de entendimento e de expressão através das linguagens da ciência (BRASIL, 2000). 
A utilização destes textos também se concretiza como uma maneira de levar para sala de aula o conhecimento acadêmico, favorecendo a democratização do conhecimento graças ao uso de instrumentos tão importantes como os TDC, gerando o diálogo no ambiente escolar e a alfabetização científica (PERY, 2005).

Dessa maneira estamos diante de um desafio pedagógico que se estabelece no uso de recursos que motive nos professores uma vontade de promover ensino de qualidade e anseio de aprender nos alunos (GOMES e ZANCUL, 2012).

Para Martins et al. (2004), os textos podem atuar de várias formas, servindo como peça motivadora, como parte das explicações, servindo ainda como provocador de debates e fonte de curiosidades, permitindo a formação de um elo entre o cotidiano dos estudantes e a ampliação de seu conhecimento.

Outro fator relevante para o uso de TDC está no tipo de discurso neles utilizado, que pode colaborar substancialmente para a elaboração do discurso escolar relativo à ciência, já que boa parte dos TDC apresenta uma linguagem semelhante àquela usada cotidianamente pelos alunos. Em outros casos há a inclusão de quadrinhos, tirinhas ou comentários com humor, além dos aspectos biográficos dos cientistas a que se referem ou mesmo fatos históricos que marcaram a produção desses conhecimentos, além de abranger possíveis consequências das produções científicas para as sociedades (ALMEIDA, 2010).

A utilização de TDC em sala de aula pode ser a princípio, um fator de insegurança para o professor. Estes textos proporcionam uma ampla possibilidade de informações com relação a assuntos variados, ao contrário dos livros didáticos que normalmente são concisos, simples e direcionados (TERRAZZAN e GABANA, 2003). No entanto, cabe ao professor um papel fundamental e definitivo no trabalho com TDC, desde a elaboração do seu planejamento até a execução de sua estratégia, uma vez que serão seus objetivos que proporcionarão as funções que os TDC terão em sala de aula (NASCIMENTO e ALVETTI, 2006).

A escola é, por excelência, um local propício à divulgação de ideias novas e ao desenvolvimento de ações que envolvam diversos temas, como por exemplo, temas relacionados às questões de saúde. Por receber educandos de várias faixas etárias e com as mais diversas experiências de vida, a escola se constitui num ambiente rico e promotor da troca de saberes. É crescente a exigência social para que se inclua a Educação em Saúde entre os objetos de ensino escolar, no entanto, busca-se o favorecimento da autonomia, a capacitação para as situações do cotidiano, a autoproteção frente a riscos e o autocontrole, exigindo educadores e materiais adequados (GAVIDIA, 2003).

Transformar a escola em um núcleo promotor de saúde, integrando escola e sociedade, partindo da premissa de agir além da sala de aula em parceria com outras entidades é a forma de ação da Escola Promotora de Saúde. Nela a educação acontece pela junção de escola, família e comunidade e não apenas por ação do currículo, assim os educadores atuam com os alunos e com a comunidade, admitindo seu papel na melhoria da sociedade (GAVIDIA, 2009).

Contudo, pesquisas indicam que a maioria dos professores utiliza apenas os livros didáticos, enfatizando e restringindo a compreensão da Educação em Saúde com cunho essencialmente biológico. Desta maneira, os temas abordados são por vezes redundantes e não despertam interesse e nem produzem modificações de hábitos e costumes (GOMES e ZANCUL, 2010).

Por meio dos programas de Educação em Saúde pretende-se capacitar o aluno para cuidar de sua própria saúde e dos demais, indo das regras básicas de higiene pessoal e coletiva às regras de segurança doméstica, de convivência, entre outros, adotando uma opção de vida que corrobore com o que Precioso (2009) chama de saúde positiva, a partir do desenvolvimento de suas potencialidades físicas, mentais e sociais. Nota-se, no entanto, que duas dimensões da Educação em Saúde estão em destaque. Uma tem como foco as doenças, sua profilaxia, complicações, consequências sobre a saúde e seu restabelecimento. A outra envolve a promoção da saúde, 
caracterizada assim pela Organização Mundial da Saúde (OMS), abrangendo os fatores sociais como agentes responsáveis por estados de saúde e bem-estar (SCHALL e STRUCHINER, 1999).

A Educação em Saúde terá seus objetivos alcançados quando puder, de fato, fomentar a conscientização nos educandos acerca de seu direito à saúde, despertar neles a necessidade de entendimento das diversas conjunturas que envolvem o tema e prepará-los para se contrapor a circunstâncias sociais estabelecidas (SANTOS e BARBONI, 2010).

Apesar de ser um tema importante e de grande interesse da população em geral, as questões referentes à alimentação estão inseridas dentro dos temas de Saúde que são tratados na disciplina Biologia. Em geral a abordagem dessa temática, na escola, está restrita ao momento que em se trata do corpo humano, sem serem consideradas as diversas questões não biológicas/interdisciplinares que se relacionam a este assunto.

Para a elaboração deste trabalho, foi considerada que a discussão a respeito de alimentação no contexto social é importante para a compreensão da dimensão que ela assume na vida das pessoas, uma vez que o ato de se alimentar inclui não apenas a ingestão alimentos, mas está relacionado, entre outros, a aspectos sociais, emocionais e culturais.

O objetivo deste estudo foi realizar uma atividade educativa com a utilização de TDC como estratégia de trabalho em Educação em Saúde na Escola, visando despertar o interesse e sensibilização dos alunos. Especificamente, discutimos possibilidades do uso de TDC como ferramenta para trabalhar o tema "Alimentação" no contexto da Educação de Jovens e Adultos (EJA).

\section{METODOLOGIA}

Este projeto foi realizado numa escola pública de Sobradinho, cidade que fica localizada no entorno de Brasília (DF), no turno noturno, no $2^{\circ}$ semestre de 2012, com alunos matriculados na Educação de Jovens e Adultos - $3^{\circ}$ segmento (Ensino Médio). Participaram vinte e quatro alunos com idades variáveis, entre 19 anos e 58 anos.

A atividade educativa foi realizada pela pesquisadora duas vezes por semana, durante 8 semanas, nos meses de outubro, novembro e dezembro de 2012, conforme os horários das aulas, sendo de 45 (quarenta e cinco) minutos cada.

Toda ação foi fundamentada tendo como base os pressupostos teóricos da Metodologia Problematizadora de Paulo Freire. De acordo com Pereira (2003) na pedagogia freireana "o método de ensino se baseia na relação dialógica entre os atores da aprendizagem, tanto alunos como professores” (p.1532). Trata-se de um processo no qual os conteúdos de aprendizagem são discutidos a partir da realidade vivenciada, e assim, alunos e professores, ao passo que aprendem, ampliam seu nível de consciência dessa realidade.

Foram desenvolvidas sete diferentes atividades: "Revistas de Divulgação Científica, muito prazer!”, “Mania de Magreza”, “Colesterol, como controlar?”, “Mas e agora, o que eu vou comer?”, “Obesidade: mais uma epidemia”, “Alimentação saudável para quê?” e "Somos o que comemos”.

Todas as intervenções tiveram como ponto de partida TDC que foram selecionados nas revistas Ciência Hoje, Scientific American Brasil, Galileu ou Superinteressante e posteriormente adaptados para que pudessem ser usados nas aulas, observando-se a extensão do texto, o tipo de linguagem utilizada, a presença de ilustrações, sua fonte e o tempo de aula disponível para a leitura do mesmo (NASCIMENTO, 2010). Todos os textos trabalhados sofreram etapas chamadas de antielaboração discursiva, visando a simplificação dos textos originais, de acordo com Nascimento e Cassiani (2010). 
A pesquisa foi norteada por uma abordagem qualitativa (BOGDAN e BIKLEN, 1994; LÜDKE e ANDRÉ, 1986). A avaliação da ação educativa foi realizada ao longo do processo e os alunos também responderam questionário de avaliação final.

\section{RESULTADOS E DISCUSSÃO}

Dentro da temática Educação em Saúde, o assunto escolhido pelos alunos, para ser trabalhado em sala de aula, foi Alimentação. As questões relacionadas à Saúde e, em especial, ao tema escolhido suscitam interesse da população em geral, e foram abordados também outros aspectos a estes associados, como os emocionais, os sociais, os psicológicos, os afetivos e os culturais.

Em cada uma das atividades propostas com o uso dos TDC os alunos eram incentivados a participar de debates e discussões, a produzir materiais e responder a questões pessoais. Durante toda a ação educativa a participação por meio de questionamentos e a busca por respostas para experiências individuais foram constantes, o que favoreceu muito os resultados alcançados.

Os temas e atividades desenvolvidas com TDC estão descritos, de maneira sucinta, no Quadro 1.

Quadro 1: Temas e atividades desenvolvidas com TDC.

TEMA E ATIVIDADES DESENVOLVIDAS

1 - Revistas de Divulgação Científica, muito prazer!: Revistas de Divulgação Científica foram distribuídas e foi proposta uma busca livre, analisando os tipos textuais, os gráficos, as figuras. Ao final, aos alunos foram solicitados a expor suas opiniões a respeito das revistas e da experiência que tiveram.

2 - Mania de Magreza: Os alunos foram dispostos em dois grupos. Cada grupo recebeu um TDC diferente sobre o tema da atividade. Após a leitura, cada grupo apresentou seu texto ao outro, partilhando os pontos comuns e divergentes. Depois os grupos elaboraram um cartaz, expondo suas conclusões a respeito das dietas, seus benefícios e necessidades.

3 - Colesterol, como controlar?: Após leitura coletiva do texto, os alunos fizeram uma listagem de sua alimentação diária e de suas atividades físicas durante uma semana. Ao lado de cada refeição e prática de exercício, os alunos colocaram um símbolo de positivo $(+)$ para aqueles itens que contribuem para a manutenção de níveis adequados de colesterol em nosso organismo ou o símbolo de negativo (-), quando apareciam itens que contribuem para o aumento do colesterol ruim. Após a atividade os alunos conversaram e trocaram experiências sobre os itens positivos e negativos, sugerindo medidas para modificar a quantidade de itens negativos identificados.

4 - Mas e agora, o que eu vou comer?: Com a turma organizada em círculo, fizemos a leitura coletiva do TDC e os alunos anotaram e marcaram no texto as ideias principais. Após a leitura fizemos uma reflexão sobre os aspectos abordados no texto e seus hábitos de consumo alimentar, a influência da mídia nos seus gastos, nos seus padrões de beleza, saúde, felicidade. Em seguida, cada aluno respondeu a uma questão pessoal: Qual a influência da mídia sobre você? Após a entrega da atividade tivemos um momento de discussão para considerações finais.

5 - Obesidade: mais uma epidemia: A atividade teve início com uma “tempestade de ideias" sobre obesidade. Em seguida foi realizada a leitura coletiva do texto e uma conversa sobre os principais aspectos que tornam a obesidade uma doença, quais seriam as medidas profiláticas e diversas questões sobre autoestima. Logo após, os alunos receberam uma atividade impressa para que respondessem sobre as principais características e complicações da obesidade. 
6 - Alimentação saudável para quê?: Com os alunos organizados em círculo, iniciamos a atividade com um questionamento: O que é uma alimentação saudável? Depois da conversa, o TDC foi distribuído e a leitura foi feita coletivamente. A cada parágrafo ou dois, a leitura era interrompida pelos comentários dos alunos sobre o tema. Após a leitura e conversa cada aluno foi convidado a responder a seguinte questão: O que é comer bem? As respostas foram entregues à professora.

7 - Somos o que comemos: Os alunos trouxeram diversos alimentos para serem partilhados num lanche coletivo. Antes da degustação, os alunos foram questionados sobre os tipos de alimentos que levaram baseado em toda a discussão que foi feita durante os encontros anteriores. Os alunos responderam ainda ao questionário final e logo depois, para encerrar a atividades, os alunos partilharam os alimentos trazidos.

Todas as atividades realizadas partiram dos conhecimentos prévios dos estudantes, que participaram ativamente das discussões, emitindo opiniões, questionando e demonstrando grande interesse pelos conteúdos presentes nos textos trabalhados em sala de aula.

Um eixo fundamental da educação popular é seu método, o qual tem como ponto inicial do processo pedagógico o conhecimento prévio dos indivíduos. Isso significa levar em conta as experiências das pessoas, reconhecendo o saber popular tão importante para o processo dialógico, quanto o saber científico (BRASIL, 2007).

Ao longo do processo, os alunos da EJA se mostraram bastante curiosos e ansiosos por informações mais específicas a respeito do tema alimentação e especialmente as que pudessem de fato colaborar com suas práticas alimentares e seus cuidados pessoais com a saúde.

Segundo Vasconcelos (2003), ainda que o conhecimento que as pessoas têm sobre saúde seja segmentado e simples, a consideração desse conhecimento no processo de aprendizagem promove o encurtamento do abismo que existe entre a ciência e a cultura da doença e da cura do cotidiano popular. É necessário considerar, também, que a manifestação do comportamento alimentar não é orientada exclusivamente pela razão, mas inclui componentes socioculturais e está intimamente relacionada aos aspectos psicológicos (GARCIA, 1999).

Os PCNs afirmam, ainda, que trabalhar com temas de Saúde na escola despertam interesse especial dos estudantes e que muitas vezes é possível partir de temas que já se encontram presentes entre os alunos e o interesse do grupo está previamente estabelecido (BRASIL, 1998), como se pode notar ao longo dessa pesquisa.

As ideias de educação popular em saúde, apoiando-se nas ideias de Paulo Freire, buscam abordagens participativas e libertadoras, indo além dos temas de higiene e doença, favorecendo uma troca de saberes entre professores e alunos (VILANOVA e MARTINS, 2008).

Em relação à ação educativa, a maior parte dos estudantes considerou como texto mais interessante "A ciência de comer bem", tratado na Atividade 6, segundo alguns alunos: "porque a gente fica sabendo como comer bem e como manter a saúde", "pois nos ensinou como se alimentar para ter uma vida saudável", "porque só assim a gente aprende a se alimentar corretamente”. No que diz respeito às atividades realizadas, foi considerada como mais interessante a confecção de cartazes. É importante ressaltar que esta foi a única atividade realizada em grupo, durante o projeto.

Quando questionados a respeito do que mais gostaram, a maioria dos alunos se referiu ao estudo em grupo: "gosto de estudar em grupo porque fica mais interessante e motiva mais os alunos a estudar", "porque podemos partilhar nossas ideias", "fiquei impressionado comigo mesmo". Ainda foram citados os debates, os trabalhos individuais e as exposições sobre os temas: "Gostei de tudo um pouco, trabalhar com textos e imagens é muito bom".

Segundo Piconez (2006), estudos têm apontado que os alunos da EJA apresentam diversos tempos e formas de aprender, o que mostra a necessidade de mudanças nas ações de ensino. Isso justifica a procura por opções de ensino mais adequadas a esse grupo de alunos, para que se estabeleça uma ligação entre o saber 
construído ao longo da vida e o saber transmitido pela escola, relacionando contextos diversos, conhecimentos anteriores e as mais diversas formas de expressão.

À medida que os textos foram sendo trabalhados nas aulas, novas situações eram pontuadas e diversas questões de saúde foram levantadas e discutidas. Os alunos também afirmaram que os aspectos de socialização e a oportunidade de trocar saberes e conhecimentos foram fundamentais. Sem dúvida, foi uma experiência diferenciada para este grupo. Os textos e as atividades a eles relacionadas proporcionaram vivências muito diferentes daquelas que eles estavam acostumados.

Situações semelhantes são mencionadas em diferentes estudos. Em trabalho realizado com alunos no Ensino Médio, na disciplina Física, Silva et al. (2007) declararam que o interesse foi tanto pelo assunto que estava sendo discutido nos TDC que o professor se viu na obrigação de interromper o que estava sendo ensinado para dar mais ênfase ao assunto dos TDC. Além disso, ressalta que a participação dos alunos foi acima da média e foi possível notar uma satisfação por parte dos alunos em aprender o que estava sendo proposto.

Em outro trabalho realizado com TDC para tratar o conteúdo “Corpo Humano” Pery (2005) aponta que os alunos reagiram positivamente às atividades propostas com o uso de revistas. Descreve ainda que ao utilizar o texto de divulgação científica em sala de aula os alunos demonstraram interesse e ressaltaram a linguagem diferenciada, que provavelmente serviu de motivação para outras fases do trabalho.

Para Rocha (2010), além de contextualizar os conteúdos trabalhados, TDC científica possibilitam a formação de cidadãos mais críticos e conscientes de sua função na sociedade. Os TDC permitem a reflexão, a interação e a interpretação dos fatos, promovendo o processo de "reelaboração" das informações pelos alunos, além de favorecer a expansão da visão de mundo dos educandos, já que consente a discussão e a troca de opiniões.

Segundo Ferreira e Queiroz (2012), a diferenciação da linguagem utilizada mostra que esse tipo de texto oferece diversas maneiras de intervenção entre leitor e a aprendizagem do objeto (GOUVÊA, 1997; MARTINS et al., 2004; AIRES et al., 2003). Estas pesquisas evidenciam ainda que os TDC, ao serem explorados em situações de ensino, ultrapassam seus desígnios originais de instrumento de divulgação, trazendo à tona suas propriedades didáticas.

Durante as atividades também foi possível constatar o aumento da participação dos estudantes na aula, inclusive na atividade realizada em grupo e nos vários momentos de reflexão. Diversos alunos que frequentavam as aulas com regularidade, mas não participavam começaram a emitir suas opiniões a respeito dos temas de saúde trabalhados, após o uso dos TDC. Tal fato corrobora com os argumentos de Pery (2005), que ressalta que os TDC proporcionaram um maior envolvimento dos alunos.

Além disso, nota-se que os TDC permitiram aos alunos, durante os momentos de intervenção, uma diversidade de possibilidades de reflexão a cerca das questões que estavam sendo tratadas e ainda permitiu o estabelecimento de debates, nos quais os alunos puderam expressar suas opiniões, seus valores e posicionamentos críticos.

Na educação problematizadora, de acordo com Freire (2005), o diálogo é fundamental e por meio dele, pela reflexão e pela ação, se pode modificar o mundo. Esse diálogo deve estar presente na educação para a liberdade, onde não há sobreposição do saberes, mas uma relação dialógica horizontal, fomentada pelo pensamento crítico que se apoia na leitura da realidade. Sendo assim, educador e educandos são sujeitos do processo com a tarefa de desvendar, conhecer e recriar o conhecimento.

E ainda comparado com outras estratégias, o uso de TDC nas aulas promove um envolvimento maior dos alunos na busca de uma compreensão mais efetiva do texto (TERRAZZAN e GABANA, 2003). 
No entanto, apesar de constatar que o trabalho com TDC têm muitos pontos favoráveis e, ao que parece, atendeu aos nossos objetivos, é necessário refletir sobre as condições básicas que envolvem sua implementação a fim de garantir uma ação positiva.

Uma limitação para o uso de TDC parece estar na dificuldade de interpretação de textos por parte de alguns alunos, como foi notado durante o trabalho em sala de aula. Apesar de ter sido realizada a adaptação do artigo e várias mediações, se nota certa dificuldade na associação das ideias abordadas no texto e de sua correlação com o cotidiano.

Diante do exposto fica claro que o uso bem sucedido de TDC em sala de aula necessita da compreensão do seu funcionamento em cada contexto, das suas condições de elaboração e de suas implicações sobre seus julgamentos, não se limitando à simples inclusão nas situações escolares (MARTINS et al., 2004).

Segundo Rocha (2010), as intervenções feitas pelos professores durante a introdução destes textos em sala de aula corroboram para a necessidade de ampliar nosso entendimento a respeito de sua inclusão didática, pois apesar de excelentes meios de divulgação científica e de fomentarem o prazer da leitura, não são tão práticos como recursos didáticos, necessitando da intervenção do professor.

Ferreira e Queiroz (2012) citam também alguns condicionantes para o uso de TDC científica nas situações de ensino, merecendo destaque uma função primordial deste tipo de texto que é a de recuperar significados mais amplos e diversificados para o ensino, se preocupando com a leitura crítica impelida pelo professor e favorecendo uma aproximação dos alunos com a linguagem científica, tendo em vista estabelecer as necessárias relações entre ciência, tecnologia e sociedade.

Nesse contexto, infere-se que a mediação do professor nas discussões e na escolha e preparo dos TDC para uso em sala de aula são fundamentais para o sucesso deste tipo de ação.

O professor precisa ter clareza quanto à finalidade por trás da eleição e uso de cada texto, uma vez que mais do que conteúdo, esses textos apresentam linguagens, enfoques, discursos e organização diferentes daqueles que caracterizam os livros didáticos (RIBEIRO e KAWAMURA, 2005).

Segundo Martins et al. (2004), há muitas formas de uso dos TDC na sala de aula, porém, em todas elas a presença do professor como mediador é fundamental, permitindo a exploração de todas as suas potencialidades.

Apesar de todas as limitações que possam ser encontradas na utilização dos TDC, por apresentarem discurso e linguagem diferenciados e por abordarem temas atuais, estes textos oferecem um enorme potencial para serem usados como ferramenta de auxílio ao professor em sala de aula (RIBEIRO e KAWAMURA, 2005).

Para Ferreira e Queiroz (2012), os TDC além de poderem ser utilizados com diferentes finalidades e objetivos, também funcionarão de diferentes formas, de acordo com a atividade proposta, com o assunto das interações, com as experiências de vida e leituras dos alunos e o de acordo com suas expectativas.

Quanto ao uso dos TDC para abordar temas de Educação em Saúde na EJA, desafio inicial deste trabalho, acreditamos que eles são fortes instrumentos para essa prática já que abrangem temas de saúde atuais e de interesse, são de fácil aquisição pelos professores, já que muitos estão disponíveis em modo eletrônico e podem ser reproduzidos para os alunos, além de todas as vantagens relacionadas ao seu uso descritas neste trabalho.

Por fim, os TDC despertam interesse nos alunos, mas entende-se que não é suficiente incluí-los nas aulas para abordar temas de Ciências. É fundamental usar os textos de maneira a envolver os alunos e muitas vezes ajuda-los a interpretar o texto. E a partir da leitura, realizar outras atividades que complementem a situação de aprendizagem criada. Por isso, utilizamos procedimentos didáticos variados procurando abordar diferentes as- 
pectos e formas de aprendizado dos conteúdos incluindo procedimentos, atitudes e valores. Relacionar o texto com as vivências pessoais dos alunos também foi uma opção sempre presente nas aulas, como forma de problematizar a realidade vivenciada com o conhecimento científico apresentado nos textos.

\section{CONSIDERAÇÕES FINAIS}

A realização deste trabalho fomentou a reflexão em torno do uso de textos de divulgação científica como forma de trabalhar temas de Educação em Saúde na escola para alunos da EJA. Foram discutidas possibilidades inerentes ao uso dos textos de divulgação científica, bem como alguns fatores limitantes.

As atividades da ação educativa realizadas alcançaram os objetivos propostos. O uso de textos de divulgação científica promoveu a reflexão e o interesse por vários assuntos de saúde relacionados ao tema Alimentação e atuou como importante elemento motivador.

Os resultados, expostos anteriormente, demonstram o grande envolvimento dos estudantes nas atividades e nas discussões, uma vez que os textos de divulgação científica relacionavam os assuntos de saúde com o cotidiano deles, favorecendo a partilha de suas experiências e a troca de saberes. Além disso, toda a ação educativa foi baseada numa relação dialógica entre os alunos e a professora.

Como os alunos da EJA apresentam características particulares de aprendizado, as estratégias de trabalho realizadas com os textos procuram atender a diversas possibilidades de envolvimento por parte dos alunos, variando entre as atividades em grupo, as questões reflexivas, a participação nas discussões ou ainda na colaboração com o lanche, na atividade final.

Diante do exposto fica claro que o uso bem sucedido de TDC em sala de aula necessita da compreensão do seu funcionamento em cada contexto, das suas condições de elaboração e de suas implicações sobre seus julgamentos, não se limitando à simples inclusão nas situações escolares (MARTINS et al., 2004).

Nesse contexto, infere-se que a mediação do professor nas discussões e na escolha e preparo dos TDC para uso em sala de aula são fundamentais para o sucesso deste tipo de ação.

Quando bem aplicados, os TDC se constituem num instrumento importante na sala de aula, especialmente para abordar os temas de Educação em Saúde, proporcionando uma alternativa viável ao livro didático.

\section{REFERÊNCIAS BIBLIOGRÁFICAS}

AIRES, J.A; BOER, N; BRANDT, C.F; FERRARI, N; GOMES, M.G; OLIVEIRA, V.L.B; PAZ, A.M; PINHEIRO, N.A.M; SCHEID, N.M.J. Divulgação científica na sala de aula: um estudo sobre a contribuição da revista ciência hoje das crianças. Anais do IV ENPEC. Bauru, São Paulo, 2003.

ALMEIDA, M.J.P.M. O texto de divulgação científica como recurso didático na mediação do discurso escolar relativo à ciência. In: PINTO, G.A. Divulgação Científica e Práticas Educativas. Curitiba: Editora CRV, 2010. p.11-23.

BUENO,W.C. Jornalismo científico como resgate da cidadania. In: MASSARANI, L.; MOREIRA, I.C.; BRITO, F. Ciência e público: caminhos da divulgação científica no Brasil. Rio de Janeiro: Casa da Ciência, UFRJ, 2002. p. 229.

BOGDAN, R.C; BIKLEN, S.K. Investigação qualitativa em educação: uma introdução à teoria e aos métodos. Portugal: Porto Editora, 1994. (Coleção Ciências da Educação). 
BRASIL, Ministério da Educação e Cultura. Secretaria de Educação Fundamental. Parâmetros curriculares nacionais: terceiro e quarto ciclos: apresentação dos temas transversais. Brasília, DF, 1998. 436p.

Secretaria da Educação Média e Tecnológica. Parâmetros Curriculares Nacionais: Ensino Médio. Parte III: Ciências da Natureza, Matemática e suas Tecnologias. Brasília: MEC, 2000 (2).

Ministério da Saúde. Secretaria de Gestão Estratégica e Participativa. Departamento de Apoio à Gestão Participativa. Caderno de educação popular e saúde. Brasília: Ministério da Saúde, 2007. 160p.

FERREIRA, L.N.A; QUEIROZ, S.L. Textos de Divulgação Científica no Ensino de Ciências: uma revisão. Alexandria Revista de Educação em Ciência e Tecnologia, v.5, n.1, p.3-31, maio 2012.

FREIRE, P. Pedagogia do oprimido. Rio de Janeiro: Paz e Terra, 2005.

GARCIA, R.W.D. A comida, a dieta, o gosto. Mudanças na cultura alimentar urbana. 1999. 140f. Tese (Doutorado) Instituto de Psicologia, USP, São Paulo, 1999.

GAVIDIA, V. La Educación para la salud en los manuales escolares españoles. Rev. Esp. Salud Publica, v.77, n.2, p.275-285, 2003.

El profesorado ante la educación y promoción de la salud en la escuela. In: Didáctica de les Ciències Experimentals i Socials., n.23, p. 171-180, 2009.

GOMES, P.H.M; ZANCUL, M.S. Educação em Saúde nos livros didáticos de ciências para o ensino fundamental. Revista da SBEnBio, n.3. p.650- 658, 2010.

GOUVÊA, G. O uso de jornais e revistas de divulgação científica no ensino de ciências. Atas do XII Simpósio nacional de Ensino de Física. Belo Horizonte: Sociedade Brasileira de Física. 1997.

KREINZ, G; PAVAN, C. Congresso Internacional de Divulgação Científica: Ética e Divulgação Científica: Os desafios do novo século. São Paulo, NJR/ECA/USP, 2004.

LÜDKE, M; ANDRÉ, M.E.D.A. Pesquisa em educação: abordagens qualitativas. São Paulo: EPU, 1986.

MARTINS, I; NASCIMENTO, T.G; ABREU, T. B. Clonagem na sala de aula: um exemplo do uso didático de um texto de divulgação científica. Investigações em Ensino de Ciências, v.9, n.1, p. 95-111, 2004.

MOREIRA, I.C. “A Divulgação Científica no Brasil”. Revista da FAPEMIG. n.18, março a maio de 2004.

NASCIMENTO, T.G; ALVETTI, M.A.S. Temas científicos contemporâneos no ensino de Biologia e Física. Ciência \& Ensino, v.1, n.1, p.29-39, 2006.

NASCIMENTO, T.G. Modos de usos de textos de divulgação científica por futuros professores de ciências. Revista da SBEnBio, n.3, p.1861 -1868, 2010.

NASCIMENTO, T.G; CASSIANI S. Funcionamento dos textos de divulgação científica na formação inicial de professores de ciências. In: PINTO, G.A. Divulgação Científica e Práticas Educativas. Curitiba: Editora CRV, 2010, 209 p.

PERY, L.C. Uso de textos de divulgação científica no conteúdo “Corpo Humano”. - UFRJ-SEE-RJ/ PROIFEN, 2005.

PEREIRA, A.L.F. As tendências pedagógicas e a prática educativa nas ciências da saúde. Caderno de Saúde Pública, v.19, n.5, p.1527-1534, 2003.

PICONEZ, S.C.B. Educação escolar de jovens e adultos: das competências sociais dos conteúdos aos desafios da cidadania. 5 ed. Campinas: Papirus, 2006. 
PINHEIRO, N.A.M; SILVEIRA, R.M.C.F; BAZZO, W.A. Ciência, tecnologia e sociedade: a relevância do enfoque CTS para o contexto do ensino médio. Ciência \& Educação, v.13, n.1, p.71-74, 2007.

PRECIOSO, J. As Escolas Promotoras de Saúde: uma via para promover a saúde e a educação para a saúde da comunidade escolar. Educação, Porto Alegre, v. 32, n. 1, p. 84-91, 2009.

RIBEIRO, R.A; KAWAMURA, M.R.D. A ciência em diferentes vozes: uma análise de textos de divulgação científica. Atas do V ENPEC, 2005.

ROCHA, M.B. Textos de divulgação científica na sala de aula: a visão do professor de ciências. Revista Augustus. Rio de Janeiro, v. 14, n. 29, p.24-34, 2010.

SANTOS, W.L.P. Educação Científica Humanística em Uma Perspectiva Freireana: Resgatando a Função do Ensino de CTS. Alexandria Revista de Educação em Ciência e Tecnologia, v.1, n.1, p. 109-131, 2008.

SANTOS, J.L.A; BARBONI, S.A.V. Educar para a saúde: a contribuição da prática docente em ciências para uma melhoria na qualidade de vida da sociedade. Revista da SBEnBio, n.3., 2010.

SCHALL, V.T.; STRUCHINER, M. Educação em Saúde:novas perspectivas. Cad. Saúde Pública. v.15, suppl.2, p. S4-S6, 1999.

SILVA, H.S.C. Artigos de divulgação científica e ensino de ciências: concepções de ciência, tecnologia e sociedade. Dissertação de mestrado. Unicamp, 2003.

SILVA, C.A.S. et al. Livro Didático X Divulgação Científica: Linguagens complementares no ensino de Física. XVII Simpósio Nacional de Ensino de Física, 2007.

TERRAZZAN, E.A; GABANA, M. Um estudo sobre o uso de atividade didática com texto de divulgação científica em aulas de física. Anais do IV ENPEC. Bauru, São Paulo, 2003.

VASCONCELOS, E.M. Educação popular, um jeito especial de conduzir o processo educativo no setor saúde. In: BRASIL, Ministério da Saúde. Secretaria de Gestão Estratégica e Participativa. Departamento de Apoio à Gestão Participativa. Caderno de educação popular e saúde. Brasília: Ministério da Saúde, 2007. 160p.

ZAMBONI, L.M.S. Cientistas, jornalistas e a divulgação científica: subjetividade e heterogeneidade no discurso da divulgação científica. Campinas: Autores Associados, 2001. 167 p. 